\title{
O POETA ENQUANTO ENSAÍSTA, MODOS DE LEITURA: MANUEL DE FrEITAS E AL BERTO
}

\section{THE POET AS ESSAYIST, METHODS OF READING: MANUEL DE FREITAS AND AL BERTO}

http://dx.doi.org/10.11606/issn.2175-3180.v13i26p14-29

Rodolpho Pereira do Amaral I

\section{RESUMO}

Este artigo procura elaborar uma dialogia entre os papéis de crítico/ensaísta e poeta praticados por Manuel de Freitas. Destacamos, num primeiro momento, alguns elementos temáticos do interesse de Freitas enquanto ensaísta da obra poética de $\mathrm{Al}$ Berto, textos trazidos a público com os títulos Noite dos Espelhos e Me, Myself and I. Em seguida, procuramos discorrer sobre os pontos sublinhados e as dimensões que assumem na obra poética de Manuel de Freitas - ou seja, de ensaísta a poeta, as duas escritas estarão em diálogo. Levamos em consideração o próprio teor crítico de Freitas, seus protocolos de leitura e recepção de obras poéticas, além da retomada pontual de outros trabalhos críticos nomeadamente Pedacinhos de Ossos e o prefácio à antologia Poetas sem qualidades. Em relação à sua obra poética, detemo-nos com mais afinco no livro Ubi Sunt, contudo não deixamos de mencionar outras produções.

\section{PALAVRAS-CHAVE}

Poesia contemporânea; Ensaio literário; Manuel de Freitas; Al Berto; Crítica.

\section{ABSTRACT}

This article seeks to develop a dialogue between the roles of criticlessist and poet played by Manuel de Freitas. We highlight, at first, some thematic elements of interest to Freitas as an essayist of $\mathrm{Al}$ Berto's poetic work, texts brought to the public with the titles Noite dos Espelhos and Me, Myself and I. Then, we try to discuss the underlined points and the dimensions they assume in Manuel de Freitas' poetic work - that is, from essayist to poet, the two writings will be in dialogue. We take into account Freitas' own critical content, his protocols for reading and receiving poetic works, in addition to the occasional resumption of other critical works namely Pedacinhos de Ossos and the preface to the anthology Poetas sem qualidades. In relation to his poetic work, we pay more attention to the book Ubi Sunt, but we did not fail to mention other productions.

\section{KEYWORDS}

Contemporary poetry; Literary essay; Manuel de Freitas; Al Berto; Criticism.

\footnotetext{
I Universidade Federal Fluminense, Niterói, Rio de Janeiro, Brasil.
} 
Parece haver um consenso a respeito de Manuel de Freitas em relação à poesia (de sua concepção à materialidade do livro): a ruptura com o instaurado. Desde a concepção da poesia, para o autor, em que a própria linguagem põe em jogo uma desestabilização, uma denúncia das linguagens hegemônicas, sobretudo a publicitária. No prefácio intitulado "O Tempo dos Puetas" (FREITAS, 2012), feito para a antologia Poetas sem Qualidades (2002), Manuel de Freitas tece considerações sobre a contemporaneidade e o reino do quantitativo, sobre as relações mercadológicas e a necessidade imperiosa de uma poesia que faça frente a essa lógica - isto é, uma poesia que faça jus à própria natureza sem qualidades para essas práticas de lucro. A materialidade, como extensão de um projeto estético, também resulta de uma preocupação com o acesso, a produção, o qualitativo em sobreposição ao quantitativo. A postura política de Manuel de Freitas perpassa, então, o modo de produção da obra, o que de articulação angaria nas comunidades a que se direciona, a circulação que rejeita aspectos predatórios. Dito de outra forma, interessa a esse autor a preocupação com o objeto em todas as suas fases, de modo a ter uma "responsabilidade estética (uma ética da contemporaneidade, se preferirmos)" (FREITAS, 2012, p. 156) com o fazer da palavra.

Esse mote leva-nos à outra questão que comumente incita leituras opostas: o círculo de eleição do poeta, isto é, a escolha de outros poetas para figurarem em antologias, ensaios, convites para publicação através de sua editora - Averno - que encabeça com a poeta Inês Dias. Se para uns essa aderência tem o peso de um poeta que fica encapsulado com outros similares no quesito ação e pensamento, para outros a escolha é desdobramento do projeto político ligado à poesia: reunir, à sua maneira, os poetas sem qualidades avessos a "certos arrebatamentos líricos mais ou menos consagrados" (FREITAS, 2012, p. 163). Interessa-nos desde já reunirmo-nos ao segundo grupo, que pensa a atitude de junção por similaridade como um gesto também poético, preocupado com a coerência de alguma poesia e a proteção que uma comunidade sólida pode vir a oferecer a seus integrantes. Esta atitude é inerente ao poeta, pois "quem constrói um poema constrói a sua assinatura, a sua morada, o seu testemunho. Essa é a condição ética da poesia" (LOPES, 2019, p. 169).

Importa discorrer sobre a nossa escolha que, inclusive, recai no próprio interesse de Manuel de Freitas em elaborar textos ensaísticos acerca 
da poesia de Al Berto. Ora, para um poeta que costuma ser cuidadoso nas suas escolhas - de leitura e de repasse numa comunidade leitora -, podemos inferir que Al Berto, no seu tempo, já preconizava as disrupturas que serão do interesse de Freitas mais tarde. Seria Al Berto, portanto, um poeta sem qualidades. Em entrevista publicada pela Revista Em Tese (2014), Manuel de Freitas diz que "Al Berto foi o primeiro poeta contemporâneo" lido na íntegra "(pouco depois da reunião da sua obra em O Medo, Lisboa, Contexto, 1987)" (CABRAL; LIMA, 2014, p. 256), aos dezesseis anos de idade. Embora jovem, no momento já despontava algo que mais tarde viria a se desenvolver como escolhas estéticas (e políticas, claro): "eu fiquei deslumbrado com aquela escrita torrencial, mesmo (ou sobretudo) no que então me parecia ter de 'incorrecta'" (CABRAL; LIMA, 2014, p. 256).

É partindo então dessa coerência de projetos poéticos - os do próprio Manuel de Freitas parelhos ou dialógicos com os de Al Berto - que desenvolveremos este artigo. Aqui, procuraremos elencar alguns destaques temáticos feitos por Manuel de Freitas nos livros ensaísticos sobre a poesia de Al Berto, nomeadamente A Noite dos Espelhos: modelos e desvios culturais na poesia de Al Berto (1999) e Me, Myself and I: autobiografia e imobilidade na poesia de Al Berto (2005), editoras Frenesi e Assírio \& Alvim, respectivamente. Esses relevos escolhidos serão considerados a tônica do fazer poético de Manuel de Freitas, ou seja, a reverberação que esses apontamentos têm na sua poesia, a tematização desses aspectos - quer por estarem num poeta de seu gosto, quer por pertencer ao leque contemporâneo (historicamente datado, assim) de temas com os quais se envolve.

A propósito de uma teoria da influência poética, ou da primeira seção do livro de ensaios A Noite dos Espelhos - nomeada de "A propósito (ou não) da influência" -, Manuel de Freitas destaca uma assertiva de Jorge Luis Borges, segundo o qual "ao criarem os seus precursores, determinados escritores alteravam inexoravelmente a leitura que daqueles possamos fazer" (BORGES, 1984, p. 123 apud FREITAS, 1999, p. 12). Desse modo, a condição de leitor que o escritor também se atribui altera a recepção e a escuta de escritas que antecederam a sua. A leitura de Freitas sobre a poesia de Al Berto, por conseguinte, retoma aspectos negligenciados por uma crítica preconceituosa e modifica em alguma medida a recepção dessa obra - evocada, inclusive, para responder às questões do próprio tempo em que é trazida. 
Para o poeta Manuel de Freitas, que se encontra em várias instâncias do fazer poético devido às funções que acumula (poeta, editor, livreiro, crítico etc.), é primordial que um dos pontos de interesse destacados na prática de escrita de Al Berto seja justamente a dupla função exercida na publicação do seu primeiro livro - À Procura do Vento num Jardim d'Agosto (1974/75). Nesse livro de estreia, o poeta será simultaneamente autor e editor, assinando ainda com o nome civil Alberto R. Pidwell Tavares. É também nesse livro que encontraremos temas caros à poesia de $\mathrm{Al}$ Berto e que serão destaques de Manuel de Freitas nos dois ensaios dedicados à literatura albertiana, nomeadamente a tendência autobiográfica na profusão de um eu insistente e multifacetado; o desdobramento "diarístico" de uma escrita que forja a intimidade, fazendo uso de elementos subjacentes a esse gênero, tais como "datação, introspeção, pendor descritivo, coincidências biográficas, etc." (FREITAS, 2005, p. 20); o caráter lisérgico que impulsiona a composição da escrita de diversas formas; além de estar documentado nesse livro de estreia a cisão do nome do próprio poeta, início de declaração que aloca o sujeito empírico (Alberto) e o sujeito da enunciação (Al Berto) dentro de uma organização textual muito particular.

Para Manuel de Freitas, a participação nos diferentes estágios de composição do livro denota um meio de tornar pessoal algo que passou a ser pensado em larga escala, afastando o autor da materialidade do objeto que produziu. Nesse sentido, há um certo jogo sobre o próprio status de raridade da poesia, essa linguagem que precisa se contrapor às hegemonias. A efetivação de acuidade com o projeto literário se dá de muitas maneiras, seja na elaboração da capa, do formato, seja na escolha dos lugares por onde o livro vai circular, para citar alguns exemplos. Uma das formas de pensar um projeto estético para além do texto escrito e que encontra recepção na leitura crítica de Freitas acerca da poesia de Al Berto é a utilização da fotografia. A inserção de outra linguagem dentro do livro assume significados variados, quer no que diz respeito ao próprio teor de autobiografia/autorrepresentação, quer no que diz respeito às simbologias das fotografias.

Foto/grafia, como grafa Manuel de Freitas na seção dedicada às suas análises, demanda algo que, para a poesia de Al Berto, também se 
torna essencial: a imobilidade. A imobilidade, em Al Berto, passa necessariamente pelo corpo, pelas corporeidades e pelas posições que assumem dentro do labor do texto. Para Freitas, "são sintomáticas, a esse respeito, as posições que a escrita incessantemente regista" (FREITAS, 2005, p. 24). Notemos:

não consigo dormir, fumo cigarros. conto e reconto os nós das madeiras. estou deitado, penso: nada me pertence aqui, tenho medo deste imobiliário, destes objetos que evocam uma infância pouco feliz. que destino dar-lhes? se não consigo lembrar-me de ter vivido no tempo que evocam (AL BERTO, 2009, p. 226).

uma ave nocturna levantou voo das palmeiras, a noite está agora impenetrável. o silêncio dos astros abate-se luminoso sobre o rosto que contempla a sua própria escuridão.

mantenho-me imóvel. penso que gostaria de falar comigo mesmo em voz alta, mas tenho receio de me acordar (AL BERTO, 2009, p. 228).

A imobilidade traz, ainda, outro aspecto parelho a si e necessário à escrita - o silêncio: "anoto essas coisas vagarosamente. escrever o menos possível. quase não gesticulo. mexo-me o absolutamente necessário. é preciso chegar ao zero, ao silêncio e à imobilidade" (AL BERTO, 2009, p. 375).

É ainda pensando a imobilidade que Freitas indica um par antitético em Al Berto: o sono e a vigília. O primeiro como a impossibilidade ou fingimento de tranquilidade; o segundo como algo que a própria escrita demanda: um estado de alerta constante. Para o autor de Me, Myself and I, "o 'fingimento' da escrita parece assim dar voz a uma zona intermédia, algures entre o deserto e o apaziguamento - apaziguamento que, nesta escrita, se apresenta frágil e provisório" (FREITAS, 2005, p. 28). A imobilidade em Al Berto, portanto, não garante o sono de tranquilidade, mas antes a atenção incessante para que o sujeito com "toxicodependência verbal" (FREITAS, 2005, p. 25) dê conta do furor do registro.

Retomando a questão da fotografia, é também em relação a ela que encontraremos outro mote albertiano amplamente desenvolvido por Freitas: a morte. A propósito da morte, a fotografia representa o congelamento do tempo que tenta segurar, ou que jamais se repetirá do mesmo jeito noutro tempo (uma dimensão performática) e que, portanto, representa a finitude daquele registro. É com Roland Barthes, em $A$ Câmara Clara (1989), que Freitas vai argumentar acerca da fotografia: 
A exposição desse corpo, que 'era novo ainda', comprova, no fundo, a fatalidade inerente à fotografia - que Barthes procurou sintetizar, ao considerá-la uma 'imagem que produz a morte, pretendendo conservar a vida' (BARTHES, 1989, p. 130). De facto, citando de novo Barthes, a fotografia imobiliza e reproduz 'o que nunca mais poderá repetir-se existencialmente’ ([BARTHES, 1989], p. 17) (FREITAS, 2005, p. 60).

Desse modo, as fotografias de si próprio, que, para Freitas, é o tipo de registro que vai suscitar interesse em Al Berto, desdobram-se em epítetos do corpo do escritor - ou as idades de Narciso, como denomina Freitas -, já que "os vestígios do 'corpo fotografado' são percebidos como cristalizações da morte, perturbantes obituários em que tudo o que deixou de existir se conjuga para afligir o olhar" (FREITAS, 1999, p. 75).

seria curioso recuar ainda mais nas datas e recolher fotografias desde criança até hoje. talvez conseguisse prever minha imagem futura, aquela que terei daqui a muitos anos, ou mesmo prever a imagem que terei no momento exacto de morrer. deve ser possível prever todas estas coisas.

mas, provavelmente, só se morre nas imagens. o que me atormenta é que estes retratos não podem sobreviver muito tempo depois de mim. e qual dele terá sido o meu verdadeiro retrato? de todos eles qual será aquele onde nunca estive? (AL BERTO, 2009, p. 460).

Estamos diante de um sujeito encenado, cuja encenação extrapola a palavra e pensa a elaboração também nos elementos pictóricos dessa literatura em que convivem simultaneamente duas narrativas: a dos poemas e a das fotografias. A essas mortes de Narciso nas fotografias Freitas dá o nome de Ars Moriendi (FREITAS, 1999, p. 75). Nesse sentido, "cada gesto - vivido ou fotografado - é essencialmente elegíaco, sem regresso" (FREITAS, 2005, p. 60).

Esta recusa de Al Berto "em ser apenas uma existência de papel" (FREITAS, 1999, p. 78), e angariada para seu projeto estético, é um reflexo de sua formação no curso de pintura monumental na École Nationale Supérieure d'Architecture et des Arts Visuels, na Bélgica. A título de ilustração, não esqueçamos os poemas contidos em A Vida Secreta das Imagens (1984/85), em que "o motivo pictórico (ou escultural, nos casos de Manuel Rosa, Rui Sanches, José Pedro Croft e Rui Chefes) pode não ser mais do que um álibi para a irrupção lírica" (FREITAS, 1999, p. 84). Pretexto ou não para a escrita do poema, Freitas insere as imagens - ou 
paratextos, como sugere Eduardo Prado Coelho (COELHO, 1987, não paginado apud FREITAS, 1999, p. 77) - no bojo estético de Al Berto; elas são também um motivo do seu fazer literário.

Continuando com a irradiação de modelos artísticos de outras ordens na poesia de Al Berto, o autor de Noite dos Espelhos aponta também as referências musicais. O cenário musical trazido por Al Berto à sua diegese é, sobretudo, soturno e reflete muito o movimento de contracultura musical dos anos 70. Verificamos, segundo Freitas, uma completa ausência de nomes e obras pertencentes à música erudita - ou clássica, mais comumente conhecida (FREITAS, 1999). Em detrimento da erudição, as influências vão ao encontro do punk do final dos anos 70, do rock e da música pop letárgica dos anos 80 . Esses gêneros musicais dariam conta da violência dos tempos e dos sentimentos que atravessaram gerações. É mais evidente tais influências nos primeiros livros de Al Berto, "escritos em pleno apogeu do punk" (FREITAS, 1999, p. 60). Em Lunário (1988), a presença dos Velvet Underground

é mais intensa e significativa, servindo de invariável pano de fundo aos bares de uma cidade híbrida e alucinante. Uma das canções de The Velvet Underground \& Nico, 'Run, Run, Run', chega mesmo a ser apresentada como o hino de um culto inabalável (FREITAS, 1999, p. 61).

Mais influente ainda, destaca Freitas, é a presença de Ian Curtis, líder dos Joy Division, que se enforca em 1980. Sua influência é tamanha que Al Berto dá título a um poema com o nome do músico - "Noite de Lisboa com Auto-Retrato e Sombra de Ian Curtis": "[...] a noite é imensa e já não tem ruídos/ a morte vem dos pés sobe à cabeça alastra ferozmente/ mas a sua inquietante brancura/ só é perceptível na súbita ereção do enforcado" (AL BERTO, 2009, p. 466). Manuel de Freitas apontará, ainda, que a inspiração é tão intensa que, no poema, é possível notar a presença de si no outro, porquanto o título nos apresenta um auto-retrato (FREITAS, 1999, p. 65). Essa atmosfera musical vai reverberar explicita e implicitamente em vários momentos d'O Medo (2009): “E é exactamente pela frieza, glacialmente sentida enquanto sinal dos tempos, que poderíamos concluir esta breve aproximação entre a nenhuma alegria de Curtis e a prostração recorrente n'O Medo" (FREITAS, 1999, p. 66).

Sobre este aspecto resta ainda pontuar que, para um poeta como $\mathrm{Al}$ Berto, que lia seus poemas - acompanhado pela guitarra de Manuel M. 
Mota - na Casa Fernando Pessoa, no Coliseu dos Recreios e no Jardim Botânico de Lisboa, a sentença de Paul Zumthor sobre a "epifania da voz viva" faz sentido (ZUMTHOR, 1987, p. 231 apud FREITAS, 1999, p. 67). Em outras palavras, mais especificamente nas de Joaquim Manuel Magalhães, "escrever é, sobretudo, ouvir escrever" (MAGALHÃES, 1989, p. 269 apud FREITAS, 1999, p. 59).

À semelhança da dicotomia sono-vigília referido acima, Freitas destaca outro par antitético presente na poesia de Al Berto, cujo desdobramento se apresenta em muitos aspectos: memória e esquecimento. Interessa-nos recortar esta antonímia no que de imperioso se vê em relação aos poemas de topos. Sem incorrer no risco de ler a obra a partir da vida do autor, mas considerando aspectos biográficos que, na obra de Al Berto, farão sentido, Freitas traz ao texto uma informação sobre a vila de Sines que nos permite ler os poemas de Mar-de-Leva (1976) dotando-os de mais sentidos. Diz-nos ele: "saber, por exemplo, que casa do poeta em Sines se erguia sobre a baía que a indústria petrolífera veio descaracterizar poderá não ser um pormenor biográfico irrelevante" (FREITAS, 1999, p. 50). É precisamente nesta publicação de 1976, um conjunto de sete poemas dedicados à vila de Sines, que Al Berto tematizará o progresso como descaracterizador da subjetividade, em que pese o fato de que as rápidas mudanças no espaço embaralham a relação do sujeito com o meio e põem a memória em risco.

\footnotetext{
chegaram as máquinas para talhar a cidade que vem das águas cresce a obra do homem, ouve-se um lento grito d'espuma [e suor na memória ficaram os sinais dos bosques ceifados, as dunas [desfeitas e algumas casas abandonadas estenderam-se tubos prateados, onde escorre o negro líquido levantaram-se imensas chaminés, serpenteiam auto-estradas na [paisagem irreconhecível do teu rosto [...] (AL BERTO, 2009, p. 155).
}

A mudança na paisagem, notemos, rouba a memória do habitante da vila. O progresso instaurado, advindo da tecnologia, retira interações humanamente possíveis com o espaço. À semelhança de Manuel de Freitas, Al Berto tem aversão à tecnologia, fato sublinhado pelo próprio Freitas: “Como para Burroughs, Al Berto também se interessa pelas máquinas, computadores e afins enquanto roubadores de memória, 
entrave ao progresso humano e, até mesmo, um totalitarismo tecnológico" (FREITAS, 1999, p. 24). Desse modo, estamos diante de uma problemática de uma das principais tarefas da memória - a escrita (FREITAS, 2005). A escrita como um mecanismo de gravação - memotecnia - possibilita, assim, uma experiência de partilha do próprio tempo, de narrativas comuns e, por isso, é também uma experiência de comunidade. A sabedoria perpassa a todos pela mediação da memória e este saber, na perspectiva apontada por Freitas, também se percebe na analogia entre o corpo da cidade e a desterritorialização do corpo do sujeito, como perda de referência deste: "não consigo dormir com esta ferida / as máquinas sussurram, trepam pelas paredes, escancaram portas, invadem / a casa, ocupam os sonhos / sirenes, alarmes lancinantes, cremalheiras da noite ressoando no limite do / corpo" (AL BERTO, 2009, p. 161).

3.

$\mathrm{Na}$ esteira de uma tradição iniciada por Baudelaire, como aponta Pedro Eiras (2007), Manuel de Freitas faz denúncias assertivas sobre o progresso. Não um progresso "universal", mas situado de maneira crítica no seu país, mais especificamente na cidade de Lisboa; o poeta é, portanto, crítico ferrenho da cultura de massificação e da mercantilização da vida no contexto português. À revelia da velocidade trazida pelas novas tecnologias e presente na diversa constelação do progresso encabeçado pelos líderes mundiais, Manuel de Freitas trará à baila, de muitas maneiras, a desaceleração da vida. Essa resistência só é possível com a lentidão que a escrita e a leitura podem proporcionar, permitindo ao sujeito contemporâneo a possibilidade de contemplação frente a um mundo que olha, mas não vê. Um certo elogio à lentidão já referido como destaque na poesia de Al Berto, em que o próprio Manuel de Freitas sublinha como inerente ao fazer poético.

A propósito do estreitamento proposto no estudo acerca de temáticas comuns aos dois poetas, há um campo semântico idêntico entre Al Berto e Manuel de Freitas: melancolia, desolação, morte, tristeza, amargura, já que são poetas que vivenciam o seu próprio tempo, um tempo de desolação e banalizações do mal e da morte.

Retomando o quesito lentidão, em Manuel de Freitas podemos destacar dois modos pelos quais o poeta tematiza esse ponto: o primeiro, está na escuta; o segundo, na observação da vida e dos transeuntes dentro 
das tabernas. Diferentemente da imobilidade fotográfica destacada em Al Berto, Freitas é um poeta essencialmente da escuta - a audição é um sentido amplamente usado nos seus poemas. De vasto conhecimento erudito, Pedro Eiras destacará a música clássica como um mote de um dos livros do poeta - Büchlein für Johann Sebastian Bach (2003):

É costume considerar que a poesia de Manuel de Freitas propõe um universo de referência (urbanas, profanas, pop, pós-modernas...) identificáveis e partilháveis pelo leitor, e isso parece-me certo; mas os títulos dos poemas deste Büchlein pedem uma decifração erudita, às vezes bastante difícil (EIRAS, 2007, p. 182).

A música erudita também se encontra na referência a Andreas Scholl, no livro Jukebox 1 \& 2 (2009), ainda segundo Pedro Eiras (2007). Mas não só de música erudita é composto o tecido poético de Manuel de Freitas. No posfácio do livro Ubi Sunt (2019), Mariano Marovatto destaca nomes que revelam uma vasta cultura musical por parte de Freitas: Chet Baker, Velvet Underground, Morton Feldman, Dolores Duran, Tom Waits, para citar alguns. Notemos a referência a Leonard Cohen (outro músico de seu gosto) em Ubi Sunt:

Acendo uma cigarrilha. É hoje, por mero acaso, o chamado 'dia da poesia'. Houve leituras, nos sítios de costume. E iniciativas várias, e muita gente interessada em ver poetas de carne e osso a lerem poetas demasiado mortos. É lá com eles. Eu prefiro ficar em casa, à espera de que Bach ou Cohen me permitam o melhor dos sonos possíveis (FREITAS, 2019, p. 18).

Os nomes supracitados podem ser largamente verificados também no livro Jukebox $1 \mathcal{E} 2$, no qual podemos verificar vários títulos de poemas com nomes de músico/banda/cantor. É importante frisar que a abertura a essas novas intertextualidades, ou melhor, referências extratextuais, refletem muito o tempo em que o poeta escreve, dotado de certa abertura para a permeabilização do texto com elementos alheios à palavra escrita seja em relação ao caráter pictórico de Al Berto, seja na dimensão musical de Manuel de Freitas. Os tempos dos poetas são de fragmentação, mas também de hibridismo de linguagem, o que solicita maior ou menor grau de circulação em diferentes formatos. Nesse sentido, as perspectivas de análise crítica vão ao encontro do que diz Ida Alves no ensaio "Paisagem, aceleração e poesia por uma geografia das emoções": 
O interesse por esse ângulo de análise é coerente com o entendimento de que estudar poesia não é se restringir a abordagens radicalmente textualistas que consideram o poema um objeto fechado e autônomo, autorreferencial e autossuficiente, mas sim uma textualidade também em movimento, que se abre ao fora de si, linguagem co-movida pelo mundo e movente de nossa percepção em relação aos outros (ALVES, 2015, p. 31).

Acerca do segundo aspecto referido acima, a taberna torna-se um locus especial para a observação do mundo, ação possível apenas pela desaceleração do olhar. Oposto a Al Berto, que deambula dentro de si analisando paisagens internas que denotam sua introspecção e seu confessionalismo - "A travessia interior, enquanto contraponto quase sempre melancólico da deambulação urbana" (FREITAS, 1999, p. 46) -, Manuel de Freitas está no espaço externo, que não deixa de conduzi-lo ao interior também, isto é, "está atento ao que se passa lá fora ao mesmo tempo em que também escreve seu próprio isolamento" (PIMENTA, 2017, p. 6132). Nesse poeta temos, então, o que Ida Alves designou como geografia das emoções, pensada "a partir de sujeitos líricos em movimento, inquietos e em busca de espaços, memórias e sensações perdidas" (ALVES, 2015, p. 31). Em "taberna com coelha no fundo", temos um sujeito lírico a pontuar figuras da taberna sem deixar também de mencionar a ausência, que se faz presente na morte do taberneiro Jorge:

A coelha mantém-se tranquila

no canto que foi aumentando

desde a recente morte do taberneiro.

Observo-a discretamente: gorda

e disforme sobre um sujo mar de jornais

[...]

Já não é o senhor Jorge, de ouvido mouco

e dedos amarelecidos pelo tabaco,

quem me serve trôpegos copos de vinho tinto.

E talvez por isso, pelo receio imbecil

de uma suposta traição, beba antes cerveja (FREITAS, 2001).

A taberna funciona como um microcosmo no universo diegético de Freitas, pese o fato de que a vida é passível de ser observada, os afetos desdobram-se nas lembranças e a memória está a todo momento 
tensionada. É também na taberna e nos cafés de Lisboa que o locus afetivo é muitas vezes demonstrado na poesia de Freitas, ora na referência a seu Manel, em "O azul, de novo", ora na preferência por Inácio, num poema que carrega seu nome:

\section{PREFIRO O INÁCIO,}

a quase todos os poetas que conheço.

Não sei se morreu ou se já não vive

- pois foi proibido de beber

e de fumar, e o Inácio era

essencialmente isso: um grande bêbedo

e um fumador diligente, que ensinara

o cão a ir junto da taberneira buscar-lhe

novo maço de tabaco. Quem viu, acredita.

Quem não viu, falhou o milagre (FREITAS, 2019, p. 13).

O par antitético memória e esquecimento está a todo o instante presente nos mais de trinta livros lançados por Manuel de Freitas. Enquanto Al Berto tece uma poética em que a memória está atrelada a si mesmo - evidência da autorreferência inerente à sua literatura -, Manuel de Freitas tem interesse numa memória dos lugares, das pessoas que os frequentavam e até de si mesmo, mas como resultado do encontro com o outro. Dois polos, então: de um lado um "narcisismo feroz" (FREITAS, 1999, p. 73) preocupado com a ruína do próprio corpo (o empírico e o textual) presente em Al Berto; de outro, a procura da memória como partilha, como construções narrativas comuns a sujeitos que dividem e frequentam o mesmo espaço, endereçamento praticado por Freitas. A propósito dessa poesia do imanente cuja relação com o tempo em que se vive é mais importante que o testemunho acerca dele, é Tamy Pimenta (2017) a trazer a ideia de literatura como construção de espaço de afeto na poesia de Freitas. Citamo-la:

Podemos observar o uso de certos mecanismos que reforçam a ideia de livro de poesia como um espaço de partilha afetiva tanto dentro dos poemas, com o uso da citação, de endereçamentos, da segunda pessoa do discurso, de tempos verbais que reforçam o diálogo ou a interpelação, dentre outros; quanto na própria elaboração dos livros, por meio das dedicatórias, notas e cunho artesanal das publicações (PIMENTA, 2017, p. 6130). 
Essa partilha a que se refere Pimenta é verificável em vários títulos de poemas presentes no livro Ubi Sunt (2019), em que o sujeito lírico parece querer associar experiências aos locais que frequenta, espaços externos, por vezes internos, e coletivos: "Rua Luciano Freire", "Largo do Calvário", "Santarém, 12 de fevereiro de 2013", "Hotel Astória, Quarto 229", para citar alguns títulos. Os poemas de topos dão a saber também o itinerário do poeta, a geografia da partilha do seu desencanto, do seu descontentamento com o mundo, que sempre foi péssimo, segundo Freitas: "Acho que todos os tempos são difíceis; o nosso tempo de vida, ao parecer pior, deve-o apenas ao facto de ser o nosso" (LEMOS, 2018, p. 296).

Por fim, outro mote da poesia de Freitas é precisamente a morte. Segundo Pedro Eiras, a morte figura como uma espécie de obsessão nessa poesia: "a pequena morte pessoal sem sentido, irreparável, [...], como todos os livros de Manuel de Freitas, não dirá, em todas as suas glosas, nenhuma vontade senão a de morrer" (EIRAS, 2007, p. 180). Estamos diante de um sujeito lírico que tematiza a morte em amplos aspectos, desde a ruína na polis e nas relações humanas, seus possíveis simulacros, até a morte efetiva de um corpo que já nasce morrendo.

'Tantas gajas!' - disse a Daniela, enquanto
o Luís nos tentava ler um elogio sumário
de John Cage. Eu, sempre mais propenso
à sombra, arruinei de vez o estore do quarto.

A Inês riu-se, sabendo da minha total imperícia, e juntos, nesse fim de tarde, reuníamos provas materiais de que uma vida é apenas uma morte. Já passou (FREITAS, 2019, p. 24).

Contudo, é justamente por esse contato tão estreito com a morte que a valorização do que é vida pulula nas páginas dos livros, aproximando mais uma vez um par de antítese: "O tempo, uma vez mais, estava contra nós. Mas tenho/ de te dizer que apertar-te a mão e reconhecer-te vivo/ me salvou de um dos piores dias que esta cidade me deu" (FREITAS, 2019, p. 25).

Num mundo megalômano em que todas as miudezas não têm valor, a figuração da pequena morte - não aquela praticada por inúmeras políticas de morte ao redor do mundo, pois essas são mortes midiatizadas e servem ao propósito do espetáculo - na poesia torna-se um ato 
imperioso, porquanto essa linguagem é contrária às hegemonias. A morte, como nos recorda Benjamin em seu ensaio "O Narrador", também possui uma disposição pedagógica, já que "na autoridade daquele que vai morrer e se recorda da vida, está a origem da narrativa (BENJAMIN, 1983, p. 199 apud PENNA, 2013, p. 54). Ou seja, a morte ensina a lidar com a memória, a narrativa, o discurso lutuoso e a condição primeira do humano - que é acabar.

A morte, como apontada por Freitas em Al Berto, assume inúmeros aspectos e desdobramentos temáticos (do pictórico à textualidade). Em Freitas, até as dedicatórias retomam o nome morto, fazem referência a essa ausência no mundo que passa a estar no agora pela linguagem poética, que retoma a nomeação no corpo textual. O nome evocado na dedicatória, para além do teor afetivo de ofertar algo a alguém, também serve de lembrete ao sujeito lírico que escreve a memória, posto que "o nosso reconhecimento enquanto mortais apenas pode ocorrer a partir da experiência da morte do outro" (DASTUR, 2012, p. 14 apud PENNA, 2013, p. 55). No poema "O azul, de novo", dedicado à memória de Rubem Fontoura, há a dolorosa associação do lugar que se visita a uma pessoa que já não está mais ali, conjugando morte e memória afetiva:

Mas o que me inquieta, cada vez que regresso, é a ausência escandalosa do Conde e da Maria Aurora. Seria simples e concludente perguntar ao Ruben o motivo dessa ausência. Receio, porém, ouvir uma resposta que é demasiado fácil adivinhar e que se mantém, afinal, a única resposta (FREITAS, 2019, p. 16).

O discurso lutuoso, arrematemos, encontra-se presente em todas as obras de Manuel de Freitas, como já referido por Pedro Eiras, praticando assim um rito de conservação que é umas das principais tarefas da memória: a escrita (FREITAS, 2005). À semelhança dos pares morte e vida, mortos, na poesia freitiana, validam ainda mais os mortais presentes no tecido do texto (amigos, familiares, personagens casuais). Parafraseando Beatriz Penna (2013), esses comparecimentos criam a comunidade dos mortais.

\section{REFERENCIAS}

AL BERTO. O Medo. Lisboa: Assírio \& Alvim, 2009. 
ALVES, Ida. "Paisagem, aceleração e poesia por uma geografia das emoções". Revista de Letras, Fortaleza, n. 34, vol. 1, p. 27-38, jan.-jun., 2015. AMARAL, Fernando Pinto. O mosaico fluido. Lisboa: Assírio \& Alvim, 1991.

CABRAL, Cleber A; LIMA, Sérgio H. S. "Roteiro de Variações: Entrevista com Manuel de Freitas". Revista Em Tese, Belo Horizonte, n. 3, vol. 20, p. 250-257, set.-dez., 2014.

EIRAS, Pedro. "Meu Deus de brincar somente - Bach na poesia de Manuel de Freitas". Cadernos de Literatura Comparada, Porto, n. 17, p. 177194, dez., 2007.

FREITAS, Manuel de. A noite de espelhos: modelos e desvios culturais na poesia de Al Berto. Lisboa: Frenesi, 1999.

FREITAS, Manuel de. Os infernos artificiais. Lisboa: Frenesi, 2001.

FREITAS, Manuel de. Me, myself and I: autobiografia e imobilidade na poesia de Al Berto. Lisboa: Assírio \& Alvim, 2005.

FREITAS, Manuel de. Jukebox 1 \& 2. Vila Real: Dom Texto, 2009.

FREITAS, Manuel de. Pedacinhos de ossos. Lisboa: Averno, 2012.

FREITAS, Manuel de. Ubi sunt. Juiz de Fora: Edições Macondo, 2019.

LEMOS, Masé. "O poeta do terceiro andar: entrevista com Manuel de Freitas". Texto Poético, São Paulo, n. 24, v. 14, p. 291-298, jan.-jun., 2018.

LIMA, Marleide Anchieta. "Entre violência e desolação: grafias do urbano na poesia portuguesa contemporânea". Revista eletrônica Literatura e Autoritarismo, Santa Maria, n. 19, p. 132-145, jan-jun, 2012.

LOPES, Silvina Rodrigues. A anomalia poética. Belo Horizonte: Chão da Feira, 2019.

PENNA, Ana Beatriz Affonso. Configurações de tempo e espaço na poética de Manuel de Freitas. In: ALVES, Ida (org.). Um corpo inenarrável e outras vozes. Niterói: EdUFF, 2010.

PENNA, Ana Beatriz Affonso. Jogos de perder: Linguagem, valor e morte na poesia de Manuel de Freitas. Dissertação (Mestrado em Estudos de Literatura) - Faculdade de Letras, Universidade Federal Fluminense, Niterói, 2013. 
PIMENTA, Tamy de Macedo. “Uma solidão solidária: poesia como comunidade de afetos em Manuel de Freitas". In: Anais Eletrônicos do XV Congresso Internacional da ABRALIC. Rio de Janeiro, UERJ, 2017. p. 6126-6134.

Recebido em 30 de julho de 2021

Aprovado em 15 de dezembro de 2021

Rodolpho Pereira do Amaral

Mestre em Estudos de Literatura (Literatura Portuguesa e Literaturas Africanas de Língua Portuguesa) pela Universidade Federal Fluminense e Licenciado em Letras (Português/Literaturas) pela Universidade Federal Rural do Rio de Janeiro, com dupla diplomação pela Faculdade de Letras da Universidade de Coimbra.

Contato: rodolph.amaral@gmail.com

(D): http://orcid.org/0000-0002-1109-8985

\begin{abstract}
A Revista Desassossego utiliza a Licença Creative Commons Attribution que permite o compartilhamento do trabalho com reconhecimento da autoria e publicação inicial neste veículo - Attribution-NonCommercial-NoDerivates 4.0 International (CC BY-NC-ND 4.0), e reconhece que os Autores têm autorização prévia para assumirem contratos adicionais separadamente para distribuição não-exclusiva de versão dos seus trabalhos publicados, desde que fique explicitado o reconhecimento de sua autoria e a publicação inicial nesta revista.
\end{abstract}

